\title{
The Relationship between Nonverbal Intelligence and Emotional Intelligence among Children in UK and Oman
}

\author{
Tagharid Bint Turki Al Said ${ }^{1}$ \\ ${ }^{1}$ Department of Psychology, Sultan Qaboos University, Sultanate of Oman \\ Correspondence: Tagharid Bint Turki Al Said, Department of Psychology, Sultan Qaboos University, Sultanate of \\ Oman. Tel: 968-9-942-2042. E-mail: ttnfm@yahoo.com or taghreed@squ.edu.om
}

Received: August 26, 2013

doi:10.5539/ijps.v6n1p79
Accepted: February 7, $2014 \quad$ Online Published: February 22, 2014

URL: http://dx.doi.org/10.5539/ijps.v6n1p79

\begin{abstract}
The study compared the relationship between nonverbal intelligence (IQ) and emotional intelligence (EQ) in Omani and British pupils, also stratified by gender and age level $(8,9,10$ years old). The tests used were Raven's Progressive Matrices Colored (CPM) and the short version of the Bar-On [Bar-On EQ-i: YV (S)] on 332 UK, and 465 Omani children. The results of the Raven test scores indicated that the largest number of British pupils fall into the fifth level (Intellectually Average $25+$ ), while the largest number of Omani pupils fall into the fourth level (Intellectually Average $50+$ ). The result of the Bar-On scale were statistically significant in the variables of state (in favour of Omani children), and age (in favour of younger age). However, differences were not significant in the variables of gender and 2-way and 3-way interactions.
\end{abstract}

Keywords: nonverbal intelligence, emotional intelligence, Omani children, British children

\section{Introduction}

Many educational and psychological studies have dealt with emotional intelligence recently, which is a relatively recent concept.

For a long time performance in cognitive intelligence tests has been an essential indicator in the process of judging individual success, and predicting his future performance in academic, professional and practical areas. However, recent studies indicate that cognitive intelligence IQ is no longer a good indicator alone (Cherniss, 2000). Some researchers emphasize that cognitive intelligence in itself is not a good indicator of an individual's performance; Hunter and Hunter (1984) found that cognitive intelligence contributes, in best conditions, to $25 \%$ of variance of individual performance. Sternberg (1997) pointed out that studies disagree. He found that $10 \%$ of variance might be a more realistic estimate than any other in contributing to performance in IQ.

A study by Stein and Book (2000) showed that emotional intelligence grows with age, until it reach its peak at the end of the forties and the beginning of the fifties according to the results of Bar-On test applied to a sample of 3831 adults from America and Canada. This result indicates that the emotional maturity of an individual comes as a result of the factors of age, experience and maturity. On the other hand, the study found that females are more conscious of emotional intelligence than males, and also more interested in the relationships between individuals and in social responsibility, while males were faster and stronger in their responses to situations that occur spontaneously.

The results of a study by Ghosn (1999) indicated that the emotional intelligence of children develops from the early years of their lives. He added that it is more reliable in predicting academic achievement than cognitive intelligence IQ. However, a high percentage of children suffer from poor indicators of emotional intelligence, which negatively affect their academic life and the level of social relationships they have.

It is already clear from the aforementioned studies of the role of cognitive intelligence IQ and emotional intelligence EQ, in the success of individuals in their study, work and their life in general. However, studies have not precisely agreed on the contribution of each type to this success. Neither have they agreed on the nature of the relationship between emotional intelligence and other types of intelligence.

It is interesting that to the best of the author's knowledge, there has been little research on cultural differences in $\mathrm{EQ}$, especially amongst children. Since EQ is more receptive to training and therefore presumably other environmental and cultural pressures, it might be supposed that EQ will differ between cultures, whilst IQ, which 
is supposedly culture-invariant, will be relatively unaffected. A comparison of EQ and IQ scores was thus examined in the following study. This also has a strong practical relevance. Although the research in this study is largely concerned with Arabic-speaking children, the majority of research in this field has been conducted in the English-speaking world. A comparison with what might be termed the "majority research culture", therefore seems appropriate in case there are fundamental differences between the two cultures.

Therefore, the present study aims to investigate nonverbal intelligence and emotional intelligence in two different cultures. The first represents the East (Oman) and the other represents the West (Britain).

\subsection{Rationale}

The importance of this study lies in the following aspects:

1) To the best of the researcher's knowledge, this is the first study conducted to investigate emotional intelligence in two different cultures. The first represents the East (Oman) and the other represents the West (Britain).

2) This study will demonstrate to what extent emotional intelligence is influenced by gender and age

3) The results of this study will contribute to the understanding of differences or similarities between Omani and British children in emotional intelligence and cognitive intelligence.

\subsection{Research Questions}

1) What is the level of IQ (as measured by the Raven coloured test) and EQ (as measured by the Bar-On test) in British and Omani school pupils?

2) Are there statistically significant differences in intelligence due to the variables of state (Britain, Oman), gender (male, female), and age $(8,9,10$ years old)?

3) Are there significant differences in EQ due to the variables of state (Britain, Oman), gender (male, female), and age level $(8,9,10$ years old)?

\section{Method}

\subsection{Participants}

Participants were a sample of 332 pupils from the United Kingdom, and 465 pupils from the Sultanate of Oman, aged between 8 and 10 years. Further details are shown in Table 1. Opportunity sampling was used. The Omani children were drawn from schools in Muscat schools, while UK participants were drawn from schools in Welsh.

Table 1. Distribution of the sample by gender, country and age

\begin{tabular}{lllll}
\hline Age & Gender & UK & Oman & Total \\
\hline 8 & Boys & 29 & 24 & 53 \\
& Girls & 29 & 25 & 54 \\
9 & Boys & 120 & 126 & 246 \\
& Girls & 94 & 124 & 218 \\
10 & Boys & 38 & 81 & 119 \\
& Girls & 22 & 85 & 107 \\
Total & & 332 & 465 & 797 \\
\hline
\end{tabular}

\subsection{Ethical Considerations}

The research on Omani children was done with the approval of the Sultanate of Oman's Ministry of Education's Technical Office for Development and Studies. Schools and pupils were selected randomly from the Governorate of Muscat (a region of Oman). In the UK schools, permission was sought first from the head teacher of each school, followed by letters to all parents of the children concerned requesting permission. Children were made aware that they did not have to participate, and could withdraw from the study at any time. A letter containing debriefing information was sent to parents of the participants.

\subsection{Materials}

IQ was measured using Raven's Coloured Progressive Matrices Test (CPM). The test consists of 36 matrices divided equally into three sets (A, AB, B). In each matrix, there are six choices (alternative answers). The test is 
used with children from the age of 5 to 11 years. The matrices in set A depend on the child's ability to complete the missing parts. The matrices in set $\mathrm{AB}$ depend on the child's ability to perceive the relationships and relations between the matrices and the six alternative answers. The matrices in set B depend on the development of the child's ability to think in abstract terms (Raven, Court, \& Raven, 1990, 2002). In the Arab world, the test has been standardized in many countries including Oman, and its psychometric properties have been found to be acceptable (Kazem et al., 2009).

EQ was tested using the Bar-On Emotional Quotient Inventory Youth Version (BarOn EQ-i: YV (S)). The EQ-i: $\mathrm{YV}(\mathrm{S})$ is a shortened version of a longer test. It was developed for situations where time is of the essence, where the individual being tested has limited reading or comprehension abilities, where the respondent might be fatigued from a longer set of items, or where multiple administrations of the instrument are desired. It was believed to be appropriate for testing large groups of mixed ability children aged between 8 and 10 years. .

The test uses five sub-scales (with six items per scale) to assess Intrapersonal attributes (the ability to understand and express feeling and needs), Interpersonal qualities (the ability to identify and respond to the feeling of others), Stress Management (the ability to manage and control emotions), Adaptability (flexibility, reality-testing and problem-solving), and Positive Impression (optimism and happiness) competencies. The sum of these scales creates a total EQ score.

The Bar-On scales are not available in Arabic, so an Arabic version of the test was created for the purpose of this study. First, the researcher translated the Bar-On EQ-i: YV (S) test from English into Arabic. Then she presented the translated test to a group of specialists in educational psychology, measurement and evaluation, for the purpose of ascertaining the accuracy of the translation, and the validity of the paragraphs and suitability for pupils in the first cycle of basic education in the Sultanate of Oman. The arbitrators agreed independently on the validity of the translated version and suggested some amendments. All amendments were incorporated in the study. Then, the amended version of the scale was presented along with the original copy to a specialist in English teaching methodology for the purpose of matching the Arabic and English versions of the test. He agreed with the translation, and did not offer any observations on them.

\subsection{Procedure}

The researcher tested all the Omani children on the Bar-On and Raven's tests. Because of logistical constraints and the (remote) possibility of comprehension problems, the UK participants were tested by undergraduate students at University of Glamorgan as part of their final year research dissertations. Application of the tests was performed in the same way in both Oman and the UK. Children were tested on the Bar-On and Raven's tests. In the UK, further tests were given to the children, but always after the Bar-On and Raven's tests, or on a separate day. Thus, as far as possible, testing was conducted in the same manner in both countries. The average duration of administration of the two measures was 28 minutes.

\subsection{Scoring}

The Raven's and Bar-On measures were scored according to standardized procedure.

\section{Results}

The Cronbach's alpha coefficients of Raven's for the responses of British and Omani pupils are shown in Table 2.

Table 2. Reliability of the Raven's test using Cronbach's alpha

\begin{tabular}{lll}
\hline Sample & Number of cases & alpha \\
\hline UK & 332 & .84 \\
Oman & 465 & .89 \\
UK and Oman & 797 & .87 \\
\hline
\end{tabular}

The set of Cronbach's alpha coefficients of response to Bar-On by British and Omani pupils are shown in Table 3. 
Table 3. Reliability of the Bar-On scale using Cronbach's alpha

\begin{tabular}{lllll}
\hline Sub scales of BarOn & $\begin{array}{l}\text { No. of } \\
\text { items }\end{array}$ & $\begin{array}{l}\text { UK } \\
(\mathrm{n}=332)\end{array}$ & $\begin{array}{l}\text { Oman } \\
(\mathrm{n}=465)\end{array}$ & $\begin{array}{l}\text { UK and } \\
(\mathrm{n}=797)\end{array}$ \\
\hline Intrapersonal & 6 & 0.31 & 0.51 & 0.44 \\
Interpersonal & 6 & 0.61 & 0.45 & 0.50 \\
Stress Management & 6 & 0.66 & 0.61 & 0.63 \\
Adaptability & 6 & 0.64 & 0.66 & 0.67 \\
Total EQ & 24 & 0.65 & 0.64 & 0.64 \\
Positive Impression & 6 & 0.32 & 0.51 & 0.51 \\
\hline
\end{tabular}

The scores for the Raven's test are summarized in Tables 4 and 5 .

Table 4. Frequencies $(\mathrm{F})$ and percentages $(\mathrm{P})$ of intelligence levels in British and Omani pupils according to Raven's coloured test

\begin{tabular}{lllll}
\hline \multirow{2}{*}{ Levels } & \multicolumn{2}{c}{ UK } & \multicolumn{2}{c}{ Oman } \\
\cline { 2 - 5 } & F & P & F & P \\
\hline Level I (Intellectually Superior 95+) & 29 & $8.7 \%$ & 27 & $5.8 \%$ \\
Level II+ (Definitely Above Average 90+) & 22 & $6.6 \%$ & 36 & $7.7 \%$ \\
Level II (Definitely Above Average 75+) & 47 & $14.2 \%$ & 115 & $24.7 \%$ \\
Level III+ (Intellectually Average 50+) & 57 & $17.2 \%$ & 142 & $30.5 \%$ \\
Level III- (Intellectually Average 25+) & 65 & $19.6 \%$ & 84 & $18.1 \%$ \\
Level IV (Definitely Below Average in Intellectual Capacity below 25) & 26 & $7.8 \%$ & 34 & $7.3 \%$ \\
Level IV- (Definitely Below Average below 10) & 55 & $16.6 \%$ & 7 & $1.5 \%$ \\
Level V- (Intellectually Impaired below 5) & 31 & $9.3 \%$ & 20 & $4.3 \%$ \\
\hline No: UK
\end{tabular}

Note: $\mathrm{UK}$ mean $=26.75$, Oman mean= 25.83 out of 36 .

Table 5. Means (M), and standard deviations (SD) of the Raven test according to gender, country, and age

\begin{tabular}{|c|c|c|c|c|c|c|c|c|c|c|}
\hline \multirow{3}{*}{ Country } & \multirow{3}{*}{ Gender } & \multirow{3}{*}{$\mathrm{N}$} & \multicolumn{6}{|c|}{ Age levels } & \multirow{2}{*}{\multicolumn{2}{|c|}{ Total }} \\
\hline & & & \multicolumn{2}{|l|}{8} & \multicolumn{2}{|l|}{9} & \multicolumn{2}{|l|}{10} & & \\
\hline & & & $\mathrm{M}$ & SD & $\mathrm{M}$ & SD & $\mathrm{M}$ & $\mathrm{SD}$ & $\mathrm{M}$ & SD \\
\hline \multirow[t]{3}{*}{ UK } & Boys & 187 & 26.45 & 4.88 & 27.12 & 5.33 & 26.71 & 6.83 & 26.93 & 5.58 \\
\hline & Girls & 145 & 25.21 & 5.43 & 26.43 & 6.02 & 28.64 & 5.59 & 26.52 & 5.89 \\
\hline & Total & 332 & 25.83 & 5.15 & 26.82 & 5.64 & 27.42 & 6.42 & 26.75 & 5.71 \\
\hline \multirow[t]{3}{*}{ Oman } & Boys & 231 & 21.21 & 6.55 & 25.27 & 6.67 & 27.15 & 6.42 & 25.51 & 6.76 \\
\hline & Girls & 234 & 25.83 & 5.15 & 26.81 & 5.64 & 27.42 & 6.42 & 26.15 & 5.88 \\
\hline & Total & 465 & 23.00 & 6.85 & 25.50 & 6.16 & 27.17 & 6.14 & 25.83 & 6.34 \\
\hline \multirow[t]{3}{*}{ Total } & Boys & 418 & 24.08 & 6.23 & 26.17 & 6.11 & 27.01 & 6.53 & 26.14 & 6.29 \\
\hline & Girls & 379 & 24.98 & 6.05 & 26.03 & 5.79 & 27.50 & 5.83 & 26.29 & 5.88 \\
\hline & Total & 797 & 24.53 & 6.13 & 26.10 & 5.95 & 27.24 & 6.20 & 26.21 & 6.10 \\
\hline
\end{tabular}

Group differences in Raven's score by age, gender and nationality were assessed using a three-way ANOVA on SPSS. The results are summarised in Table 6 . 
Table 6. Results of 3-way ANOVA on Raven's test according to gender, country, and age

\begin{tabular}{lllllll}
\hline Source & $\begin{array}{l}\text { Sum of } \\
\text { Squares }\end{array}$ & df & Mean Square & F & Sig. & $\begin{array}{l}\text { Partial Eta } \\
\text { Squared }\end{array}$ \\
\hline Country (a) & 305.42 & 1 & 305.42 & $8.45^{*}$ & 0.01 & 0.01 \\
Gender (b) & 57.21 & 1 & 57.21 & 1.58 & 0.21 & 0.00 \\
Age (c) & 597.19 & 2 & 298.59 & $8.26^{*}$ & 0.01 & 0.02 \\
$($ a) $\times($ b) & 57.59 & 1 & 57.59 & 1.59 & 0.21 & 0.00 \\
$($ a) $\times($ c) & 91.59 & 2 & 45.80 & 1.27 & 0.28 & 0.00 \\
$($ b) $\times($ c $)$ & 58.21 & 2 & 29.10 & 0.81 & 0.45 & 0.00 \\
$($ a) $\times($ b) $\times($ c) & 180.26 & 2 & 90.13 & 2.49 & 0.08 & 0.01 \\
Error & 28366.51 & 785 & 36.14 & & & \\
\hline
\end{tabular}

* Significant at the level of $\leq 0.01$.

The scores for the Bar-On test are summarised in Table 7.

Table 7. Means (M), and standard deviations (SD) of BarOn scale according to gender, country, and age

\begin{tabular}{|c|c|c|c|c|c|c|c|}
\hline \multirow{2}{*}{ Country } & \multirow{2}{*}{ Sub scale of BarOn } & \multicolumn{3}{|c|}{ Boys } & \multicolumn{3}{|c|}{ Girls } \\
\hline & & 8 & 9 & 10 & 8 & 9 & 10 \\
\hline \multirow[t]{12}{*}{ UK } & Intrapersonal & 14.86 & 14.60 & 14.78 & 14.69 & 14.93 & 14.41 \\
\hline & & $(2.72)$ & $(3.35)$ & $(3.06)$ & $(2.52)$ & $(2.91)$ & (3.16) \\
\hline & Interpersonal & 19.38 & 17.06 & 17.39 & 19.17 & 18.35 & 19.36 \\
\hline & & $(3.27)$ & $(3.46)$ & $(3.46)$ & $(2.94)$ & $(3.74)$ & (3.17) \\
\hline & Stress Management & 14.00 & 13.56 & 13.68 & 12.69 & 13.03 & 13.45 \\
\hline & & $(4.08)$ & $(4.17)$ & $(4.42)$ & $(3.67)$ & $(3.77)$ & $(4.86)$ \\
\hline & Adaptability & 17.14 & 16.05 & 16.24 & 16.38 & 15.91 & 16.05 \\
\hline & & $(2.82)$ & $(3.86)$ & $(4.52)$ & $(3.43)$ & $(3.41)$ & $(3.43)$ \\
\hline & Total EQ & 65.38 & 61.27 & 62.11 & 62.93 & 62.22 & 62.27 \\
\hline & & $(5.69)$ & $(9.02)$ & $(8.54)$ & $(7.89)$ & $(8.52)$ & $(8.75)$ \\
\hline & Positive Impression & 16.55 & 15.17 & 16.18 & 16.59 & 15.88 & 14.82 \\
\hline & & $(3.11)$ & $(2.91)$ & $(2.79)$ & $(2.20)$ & $(2.79)$ & (2.61) \\
\hline \multirow[t]{12}{*}{ Oman } & Intrapersonal & 14.08 & 15.52 & 14.88 & 15.80 & 15.38 & 14.87 \\
\hline & & $(3.86)$ & $(3.43)$ & $(2.97)$ & $(4.02)$ & $(3.72)$ & (3.60) \\
\hline & Interpersonal & 18.63 & 17.63 & 18.31 & 18.92 & 18.35 & 18.56 \\
\hline & & $(2.81)$ & $(3.20)$ & $(3.25)$ & $(3.71)$ & $(2.97)$ & (3.15) \\
\hline & Stress Management & 13.08 & 12.56 & 12.41 & 14.16 & 11.90 & 12.45 \\
\hline & & $(3.97)$ & $(3.62)$ & $(3.95)$ & $(3.60)$ & $(3.77)$ & (3.66) \\
\hline & Adaptability & 18.04 & 18.14 & 17.67 & 17.88 & 17.93 & 18.22 \\
\hline & & $(3.64)$ & $(3.44)$ & $(3.84)$ & $(3.83)$ & $(3.35)$ & $(3.53)$ \\
\hline & Total EQ & 63.83 & 63.86 & 63.26 & 66.76 & 63.56 & 64.11 \\
\hline & & $(8.21)$ & $(7.65)$ & $(8.82)$ & $(9.13)$ & $(8.21)$ & $(8.57)$ \\
\hline & Positive Impression & 17.83 & 17.96 & 17.89 & 18.40 & 18.64 & 18.36 \\
\hline & & $(3.40)$ & $(3.22)$ & $(2.77)$ & $(3.80)$ & $(3.03)$ & (3.07) \\
\hline
\end{tabular}




\begin{tabular}{|c|c|c|c|c|c|c|c|}
\hline \multirow[t]{12}{*}{ Total } & \multirow[t]{2}{*}{ Intrapersonal } & 14.51 & 15.07 & 14.85 & 15.20 & 15.18 & 14.57 \\
\hline & & $(3.27)$ & $(3.42)$ & (2.99) & $(3.32)$ & $(3.39)$ & $(3.55)$ \\
\hline & \multirow[t]{2}{*}{ Interpersonal } & 19.04 & 17.35 & 18.02 & 19.06 & 18.35 & 18.73 \\
\hline & & $(3.06)$ & $(3.34)$ & $(3.33)$ & $(3.29)$ & $(3.32)$ & (3.16) \\
\hline & \multirow[t]{2}{*}{ Stress Management } & 13.58 & 13.04 & 12.82 & 13.37 & 12.39 & 12.65 \\
\hline & & $(4.16)$ & $(3.92)$ & (4.13) & $(3.68)$ & $(3.80)$ & (3.93) \\
\hline & \multirow[t]{2}{*}{ Adaptability } & 17.55 & 17.12 & 17.22 & 17.07 & 17.06 & 17.78 \\
\hline & & $(3.22)$ & $(3.79)$ & (4.09) & $(3.67)$ & $(3.51)$ & $(3.61)$ \\
\hline & \multirow[t]{2}{*}{ Total EQ } & 64.68 & 62.59 & 62.90 & 64.70 & 62.98 & 63.73 \\
\hline & & $(6.92)$ & $(8.43)$ & $(8.70)$ & $(8.63)$ & $(8.35)$ & $(8.60)$ \\
\hline & \multirow[t]{2}{*}{ Positive Impression } & 17.13 & 16.60 & 17.34 & 17.43 & 17.45 & 17.64 \\
\hline & & $(3.28)$ & $(3.37)$ & (2.88) & (3.15) & (3.23) & (3.30) \\
\hline
\end{tabular}

To assess national differences in Bar-On scores, a four-way mixed ANCOVA was conducted, with between-subjects variables of age, gender and nationality and within-subjects variable of Bar-On score (five levels). To control for national differences in Raven's scores, Raven's test score was entered as a covariate. The results are summarised in Table 8 .

Table 8. Result of 4-way mixed ANCOVA with between-subjects variables of nationality, age and gender of Bar-On scores

\begin{tabular}{lllllll}
\hline Source & SS & df & MS & F & Sig. & $\eta_{\mathrm{p}}^{2}$ \\
\hline Raven & 347.04 & 5 & 69.41 & $4.71^{*}$ & .00 & .01 \\
Nationality & 817.19 & 5 & 163.44 & $11.08^{*}$ & .00 & .01 \\
Age & 336.98 & 10 & 33.70 & $2.28^{*}$ & .01 & .01 \\
Gender & 73.66 & 5 & 14.73 & 1.00 & .42 & .00 \\
Nationality $\times$ Age & 93.87 & 10 & 9.39 & .64 & .78 & .00 \\
Nationality $\times$ Gender & 92.93 & 5 & 18.59 & 1.26 & .28 & .00 \\
Age $\times$ Gender & 114.69 & 10 & 11.47 & .78 & .65 & .00 \\
Nationality $\times$ Age $\times$ Gender & 179.57 & 10 & 17.96 & 1.22 & .27 & .00 \\
Error & 57825.94 & 3920 & 14.75 & & & \\
\hline Signiffca & & & & & &
\end{tabular}

* Significant at the level of $\leq 0.01$.

As can be seen, there were significant nationality and age differences. With regard to nationality Omani children scored higher EQs than UK children. For age, post-hoc Scheffe tests revealed higher EQ score in younger children 8 years than older children 10 years.

\section{Discussion}

The results of the Raven's CPM test indicated that the largest number of British pupils fall into the fifth level (Intellectually Average 25+), while the largest number of Omani pupils fall in the fourth level (Intellectually Average $50+$ ). These minor differences between the two samples could be attributed to the nature of the times in which we live and what it imposes on us from cultural, technological, and educational convergence. The world today has become a small village, and what is happening somewhere on the earth's surface can be known by any other person anywhere else. The researcher through teaching at the university, and being a mother, has observed that children who transit from one country to another, accompanied by their families for study or work, do not confront major obstacles in their academic achievements. This rapid academic adaptation reflects the convergence in IQ levels, which was revealed by the current study. 
The results of the Bar-On scale indicated that while the level of EQ in British and Omani pupils was high in interpersonal, adaptability, positive impression and total EQ, the intrapersonal was low in both samples. Furthermore, stress management was low in the British sample and moderate in the Omani sample.

The similarities between the results of the British and the Omani samples in the high level sub-scales confirm the forgoing interpretation of cultural convergence between the peoples of the world. Whereas, the decline of emotional management in pupils of the two samples could be attributed to the sample's age group, according to the results of Stein and Book (2000) whose study described in the introduction of the current study, states that EQ develops with age and it reaches its ultimate stage by the end of the forties and the beginning of the fifties. Thus, emotional maturity emerges as the result of age and maturity.

As for the impact of gender, age, and country in cognitive intelligence (IQ) the differences were significant in the country variable (in favour of British pupils) and age variable (in favour of the older age group), and was not significant in the gender variable and in 2-way and 3-way interactions. The increase in average cognitive intelligence (IQ) for the British pupils may reflect the richness of the environment in Western countries compared to Eastern countries. The benefits of the efforts that have been done to promote education in the sultanate of Oman has been acknowledged in various fields (Ministry of Education, 2006, 2012), but there are still challenges and aspects which need more attention. With regard to the two variables; age (significant to older age group), and gender (not significant) the results are consistent with many previous studies using children of similar ages (e. g. Abu Hatab et al., 1979; Al-Heeti et al., 1995; Al-Khateeb \& Al-Mutawakil, 2001; Al-Khateeb et al., 2006; Al-Qurashi, 1987; Eid, 1999; Lynn, 1994; Lynn et al., 2004; Raven, 2000).

To determine the impact of gender, age, and country in EQ differences were significant in country variables (in favour of the Omani pupils), age variable (in favour of the younger age group), and insignificant in the gender variable and in 2-way and 3-way interactions. The insignificant differences between the two genders in EQ in the British and the Omani sample differs with the findings of Stein and Book's (2000) study which concluded that females are more aware and caring than males in the field of human relations and social responsibilities. Whereas, the male's responses are faster and stronger in the unanticipated events. The results of the age variable differs from the previous study's findings, for example Stein and Book's (2000) study concluded that EQ develops with age until it reaches its ultimate stage at the end of the forties and the beginning of the fifties. It also upheld the results of Ghosn's (1999) study, that EQ develops among children at early stages in their lives, although it shows there are quite a number of children who suffer from weak EQ indicators. The decline of EQ at the age of 9 or 10 years can be attributed to the nature of the middle childhood stage, and to the closeness in age between the age groups in the study sample. Difference are expected to appear between older age groups, because the difference between children aged 9 and 10 years is very small.

The results thus indicate some cultural differences between the two samples. It is possible that some of the differences might be attributable to different people conducting the testing, but the test presentation was standardized and the testers were rehearsed in test administration to attempt to create uniformity of presentation. However, what is perhaps more remarkable is not the dissimilarities but the fact that overall, the samples are very similar in many important respects. It is a commonplace to talk about 'the global village' and suchlike, but the results indicate that findings in one culture might, with relatively small allowances, be applicable in others, even allowing for considerable cultural differences.

\section{Recommendations}

The education of children should give priority to emotional factors studied in this study as they play an important role in the development of children's personalities.

\section{Suggestions}

1) To administer a similar study where a bigger sample of students from year 1 to year 12 is included.

2) To tailor a training programme based on developing EQ in pupils from class 1 to 4 .

\section{References}

Abu, H. F., Zahran, H., Sadeq, A., Kheder, A., Zamzami, A., Yousef, M. J., ... Bader, F. (1979). The standardization of Raven's standard progressive matrices in the Saudi culture, West region. Makka Al-Mukarama: Umm Al-QuraUniversity Publication (In Arabic).

Al-Heeti, K. N., Ganim, A., Al- Zubaidi, A., \& Alnood, Y. (1995). The standardization of Raven `s coloured progressive matrices for basic education children between 6-11 years old in the Republic of Yemen. Unpublished manuscript presented to the UNCIF (in Arabic). 
Al-Khateeb, M. A. M., \& Al-Mutawakil, M. (2001). The standardization of Raven's coloured progressive matrices test for basic education students in Khartoum City. Khartoum: Sudan Press Company Limited (In Arabic).

Al-Khateeb, M. A. M., Mustaafa, M. M. A., \& Hussein, A. M. (2006). User's guide to the Raven standard progressive matrices test in Sudan's culture. Khartoum: Money Press Company Limited (In Arabic).

Al-Qurashi, A. (1987). Raven's coloured progressive matrices test: User guide. Kuwait: Dar Alqalam (In Arabic).

Cherniss, C. (2000). Emotional intelligence: What it is and why it matters. Paper Presented at the Annual Meeting of the Society for Industrial and Organizational Psychology. New Orleans.

Eid, A. (1999). The application manual for Raven's coloured progressive matrices. Unpublished manuscript, Ministry of Education, United Arab Emirates (In Arabic).

Ghosn, I. K. (1999). Emotional Intelligence through Literature. Paper presented at the Annual Meeting of Teachers of English to Speakers of Other Languages (33rd, New York, NY, March 9-13).

Hunter, J. E., \& Hunter, R. F. (1984). Validity and utility of alternative predictors of job performance. Psychological Bulletin, 96(1), 72-93. http://dx.doi.org/10.1037/0033-2909.96.1.72

Kazem, A. M., Al-Zubaidi, A. S., Alkharusi, H. A., Yousif, Y. H., Alsarmi, A. M., Al-Bulushi, S. S., ... Alshammary, B. M. (2009). A Normative study of the Raven Coloured Progressive Matrices Test for Omani children aged 5 through 11 years. Malaysian Journal of Education, 34(1), 37-51.

Lynn, R. (1994). Sex differences in intelligence and brain size: A paradox resolved. Personality and Individual Differences, 17, 257-271. http://dx.doi.org/10.1016/0191-8869(94)90030-2

Lynn, R., Allik, J., Pullmann, H., \& Laidra, K. (2004). Sex differences on the progressive matrices among adolescents: Some data from estonia. Personality and Individual Differences, 36(6), 1249-1255. $\mathrm{http}: / / \mathrm{dx}$.doi.org/10.1016/S0191-8869(02)00240-4

Ministry of Education. (2006). From access to success: Education for All (EFA) in the Sultanate of Oman (1970-2005). Muscat: Author.

Ministry of Education. (2012). Education in Oman: The drive for quality. Muscat: Author.

Raven, J. (2000). The Raven's progressive matrices: Change and stability over culture and time. Cognitive Psychology, 41(1), 1-48. http://dx.doi.org/10.1006/cogp.1999.0735

Raven, J. C., Court, J. H., \& Raven, J. (1990). Manual for Raven's progressive matrices and vocabulary scales: American and international norms. Oxford, England: Oxford Psychological Press.

Raven, J. C., Court, J. H., \& Raven, J. (2002). Raven's colored progressive matrices. Austria: Dr. G. SchuhfriedGes M. B. H.

Stein, S., \& Book, H. (2000). The EQ Edge: Emotional intelligence and your success. Toronto: Stoddart.

Sternberg, R. (1997). Successful intelligence. Executive Excellence, 14(8), 5.

\section{Copyrights}

Copyright for this article is retained by the author(s), with first publication rights granted to the journal.

This is an open-access article distributed under the terms and conditions of the Creative Commons Attribution license (http://creativecommons.org/licenses/by/3.0/). 